\title{
The Efficacy of Kinesiology Taping in Supporting the Medial Longitudinal Arch in Patients with Unilateral Plantar Fasciitis
}

\author{
Ünilateral Plantar Fasiitli Hastalarda Medial Longitudinal Arkı \\ Destekleyen Kinezyolojik Bant Uygulamasının Etkinliği
}

\author{
Banu Ordahan \\ Department of Physical Medicine and Rehabilitation, Konya Education and Training Hospital, Konya, Turkey
}

B. Ordahan

0000-0003-2221-2728

Geliș Tarihi / Date Received: 07.03.2018

Kabul Tarihi / Date Accepted: 23.04.2018

Yayın Tarihi/Published Online: 01.08.2018

\section{Yazısma Adresi /}

Corresponding Author:

Banu Ordahan

Fiziksel Tıp ve Rehabilitasyon

Bölümü, Konya Eğitim ve

Araştırma Hastanesi, Konya,

Turkey

E-mail:banuordahan@gmail.com

(C2018 Türkiye Spor Hekimleri Derneği. Tüm hakları saklıdır.

\section{ABSTRACT}

Objective:To evaluate the efficacy of kinesiology taping (KT) that supports the medial longutidunal arch in patients with unilateral plantar fasciitis.

Materials and methods: A total of 76 patients with unilateral plantar fasciitis were included in the study. Patients were randomized into two groups as kinesiology taping (KT) and exercise groups. The exercise group was prescribed plantar fascia stretching exercise and silicone insoles. The KT group were applied a total of three weeks of kinesiology taping, once every five days, in addition to that in the exercise group. Patients were assessed before and three weeks after the treatment with visual pain scale (VAS) and heel tenderness index ( $\mathrm{HTI})$ for pain; and with foot ankle outcome score (FAOS) for functional status, and quality of life.

Results: KT and exercise groups were similar in terms of age, gender and body mass index $(p>0.05)$. At the beginning of the study, there was no statistically significant difference between the two groups in terms of VAS, HTI and FAOS scores $(p>0.05)$. After treatment, both groups revealed statistically significant improvements in VAS, HTI and FAOS scores compared with pretreatment $(p<0.05)$, the results in the KT group being better.

Conclusions: KT has yielded positive effects on pain, functional status, and quality of life in patients with $\mathrm{PF}$.

Keywords: Kinesio taping, plantar fasciitis, pain

\section{öz}

Amaç: Ünilateral plantar fasiitli hastalarda medial longitudinal arkı destekleyen kinezyolojik bant (KB) uygulamasının etkinliğini değerlendirmektir.

Gereç ve Yöntemler: Ünilateral plantar fasiit tanısı konulmuş 76 hasta çalışmaya alındı. Hastalar kinezyolojik bant ve egzersiz grubu olarak iki gruba randomize edildi. Egzersiz grubundaki hastalara plantar fasya germe egzersizi ve silikon tabanlık verildi. KB grubundaki hastalara bunlara ek olarak, beş günde bir olmak üzere toplam üç hafta kinezyolojik bant uygulandı. Tedaviden önce ve tedaviden sonra üçüncü haftada hastaların ağrı düzeyleri vizüel ağrı skalası (VAS) ve topuk hassasiyet indeksi (THI) ile; fonksiyonel durum ve yaşam kalitesi ise ayak-ayak bileği sonuç skalası (AASS), ile değerlendirildi.

Bulgular: KB ve egzersiz grupları yaş, cinsiyet ve vücut kütle indeksi açısından benzerdi $(p>0.05)$. Çalışma başlangıcında VAS, THI ve AASS skorlarında her iki grup arasında istatistiksel olarak anlamlı fark yoktu $(p>0.05)$. Tedavi sonrasında her iki grupta da, tedavi öncesiyle kıyaslandığında VAS, THI ve AASS skorlarında istatistiksel olarak anlamlı düzelme saptanırken $(p<0.05)$, KB grubunda sonuçlar daha iyiydi. 
Sonuçlar: PF'li hastalarda kinezyolojik bant uygulamasının ağrı, fonksiyonel durum ve yaşam kalitesi üzerine olumlu etkisi gösterildi.

Anahtar Sözcükler: Kinezyolojik bant, plantar fasiit, ağrı

Available at: http://journalofsportsmedicine.org and http://dx.doi.org/10.5152/tjsm.2018.099

Cite this article as: Ordahan B. The efficacy of kinesiology taping in supporting the medial longitudinal arch in patients with unilateral plantar fasciitis. Turk J Sports Med. 2018;53(3):116-22.

\section{GíRiş}

Plantar fasiit, ayağın plantar bölgesinde, sıklıkla kalkaneal tuberkülin medial tarafında ağrıya sebep olan yaygin bir problemdir. Kesin etyolojisi bilinmemektedir. Patogenezde obezite, pes planus, pes cavus, aşırı kullanım gibi predispozan faktörler rol oynamaktadır (1-3). Plantar fasyanın proksimalindeki enflame dokuda kalsifikasyon olması kalkaneal spur olarak adlandırılmaktadır. Plantar fasiitli hastalarda kalkaneal spur sıklıkla saptanır (1-5). Sabahları veya istirahat sonrası ilk adımda ortaya çıkan ağrı plantar fasiit için tipiktir $(4,5)$. Birkaç adımdan sonra ağrı azalabilir, ancak uzun süreli ayakta durma ve merdiven çıkma sırasında ağrı yoğunlaşabilir. Plantar fasyanın gerilmesi, topuk üzerine yük verme semptomları aktive etmektedir $(1,5)$.

Plantar fasiitin tedavisi konservatiftir. Konservatif tedavinin hastaların yaklașı \%90'nında önemli bir rahatlama sağladığı belirtilmektedir $(1,2)$. Non-steroid antienflamatuar ilaçlar, lokal steroid enjeksiyonları, topuk yastıkları, ayakkabı modifikasyonları, plantar fasya germe egzersizleri, elektroterapi tedavide kullanılan konservatif yöntemlerdir (6-10). Plantar fasiit tedavisinde kullanılan bir diğer tedavi yöntemi de kinezyolojik bantlama tekniği ve kinezyolojik banttır. Kinezyolojik bantlama bașta kas iskelet sisteminde olmak üzere çok geniş endikasyon alanına sahiptir. Bu teknik, deri ve subkutan dokuların yükselmesine bağlı, dolaşımı ve hareket etmeyi kolaylaştırmakta, enflamasyon ve ağrıyı azaltarak iyileşmeyi uyarmaktadır $(11,12)$. Lowdye bantlama tekniği, plantar fasiit tedavisinde en yaygın kullanılan tekniklerden biridir (13).

$\mathrm{Bu}$ çalışmada, plantar fasiit tanısı konulan hastalarda farklı bir uygulama tekniği olarak medial longitudinal arkı destekleyen bantlamanın etkinliğinin değerlendirilmesi amaçlandı.

\section{GEREÇ ve YÖNTEMLER}

Çalışmaya Fiziksel Tıp ve Rehabilitasyon Bölümü polikliniklerine tek taraflı topuk ağrısı ile başvuran toplam 76 hasta alındı. Çalışma, Selçuk Üniversitesi Tıp Fakültesi yerel araştırma etik komiteleri tarafından onaylandı. PF tanısı için, kalkaneusun medial tüberkülüne lokalize hassasiyet ve sabahın ilk adımında başlayan aktivite ile kötüleşen ağrı temel alındı. Steroid enjeksiyon öyküsü olan, romatolojik hastalığı bulunan, ayak bölgesinden operasyon geçirmiş olan ve lomber disk hernisine bağlı radiküler ağrısı bulunan hastalar çalıma dışı bırakıldı. Hastalar kinezyolojik bantlama (KB) ve egzersiz grubu olarak iki gruba randomize edildi. KB grubundaki hastalara beş gün arayla toplam üç hafta boyunca kinezyolojik bant, plantar fasya ve aşil tendon germe egzersizleri ve silikon tabanlık uygulandı. Egzersiz grubundaki hastalara plantar fasya ve aşil tendon germe egzersizleri ve silikon tabanlık verildi.

Plantar fasya ve așil tendon germe egzersizleri, self germe şeklinde günde iki kez, $30 \mathrm{~s}$ süreyle, 10 tekrarlı olarak ev programı şeklinde uygulatıldı. Egzersizler deneyimli bir fizyoterapist tarafından gösterildi. Hastalar tedaviden önce ve tedavi sonrası üçüncü haftada değerlendirildi. Randomizasyon basit kura yöntemiyle yapıldı. KB grubundan bir hasta tedaviye düzenli gelmediği için, egzersiz grubundan bir hasta tedaviyi düzenli uygulamadığı için çalışma dışı bırakıldı (Şekil 1). 




Şekil 1. Çalışma akış şeması

\section{Kinezyolojik bantlama uygulaması}

Bantlama hastanın diz ve ayak eklemi nötral pozisyonda olacak şekilde uygulandı. Birinci şerit maksimum germe yapılarak kalkaneustan ayak parmaklarına doğru plantar fasya boyunca yapıştırıldı. Diğer dört şerit bant medial longitudinal arkı destekleyecek şekilde $45^{\circ}$ eğimli olmak üzere bir medial bir lateral olarak yapıştırıldı. Bandın orta 1/3 kısmına maksimum germe yapılırken, uç kısımlarına germe uygulamadan yapıștırıldı (9). Low-dye tekniğine benzerlik göstermekle birlikte, bez bant yerine elastik bant kullanıldı. Çalışma için kullanılan bant (KinesioTex, KinesioTaping, US) su geçirmez, gözenekli ve yapışkandı (Şekil 2).

Hastaların ağrı düzeyleri vizüel ağrı skalası (VAS) ve topuk hassasiyet indeksi (THI) ile; fonksiyonel durum ve yaşam kalitesi ise ayakayak bileği sonuç skalası (AASS) ile tedaviden önce ve tedavinin üç hafta sonrasında değerlendirildi. Ağrı düzeyleri, 100 mm'lik yatay görsel analog skala (VAS) kullanılarak değerlendirildi.

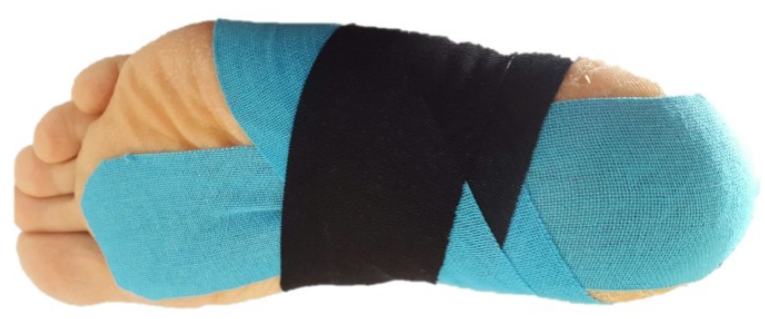

Şekil 2. Kinezyolojik bantlama uygulaması

THI ile plantar fasyanın kalkaneusa yapışma yerinin presyonla hassasiyeti değerlendirildi. $0=$ ağrı yok, 1=ağrılı, 2=ağrılı ve geri çekme eğiliminde, $3=$ =ărılı ve ayağını tamamen geri çekiyor.

Fonksiyon ve yaşam kalitesi, ayak-ayak bileği sonuç skoru (AASS) kullanılarak ölçüldü (14). AAOS; ağrı, diğer semptomlar, günlük yaşam aktiviteleri, spor ve rekreasyon fonksiyonu ile ayak ve ayak bileği ile ilişkili yaşam kalitesi olmak üzere beş alt ölüme ayrılmış 42 maddelik 
bir ankettir. Ağrı alt ölçeği dokuz madde içermekte, diğer belirtiler alt ölçeği yedi madde içermektedir. Günlük yaşam aktiviteleri alt ölçekleri 17 madde; spor ve rekreasyon fonksiyonu alt ölçeği beş madde; ayak ve ayak bileği ile ilişkili yaşam kalitesi alt ölçeği ise dört madde içermektedir. Her soru, 5 puanlı Likert ölçeğinde (0-4 arası) puanlanır ve beş alt ölçek skorunun her biri, verilen alt ölçek öğelerinin eklenmesiyle hesaplanır. Ham skorlar daha sonra 0'dan 100'e (en kötü sonuçlardan en iyi sonuçlara) kadar skorlanan son bir puana dönüștürülür. Karatepe ve ark. tarafından Türkçe geçerlilik ve güvenilirliği yapılmıştır (14). Ölçekler araștırmacı tarafından dolduruldu.

\section{İstatistiksel Analiz}

İstatistiksel değerlendirmede elde edilen veriler SPSS v11.0 (SPSS for Windows, version 11.0, released 2007, SPSS Inc., Chicago, USA) programı kullanılarak değerlendirildi. Verilerin normal dağılıma uygunluğu Kolmogorov-Smirnov testi ile belirlendi. Grup içi parametrik, bağımlı verilerin karşılaştırılmasında (paired samples ttest) kullanıldı. Gruplar arası parametrik bağımsız verilerin karşılaştırılmasında (student $t$-test) kullanıldı. Anlamlılık düzeyi olarak p <0.05 kabul edildi.

\section{BULGULAR}

KB ve egzersiz grupları yaş, cinsiyet ve vücut kütle indeksi açısından benzerdi ( $p>0.05$ ) (Tablo 1). Çalışma başlangıcında VAS, THI ve AASS skorlarında her iki grup arasında istatistiksel olarak anlamlı fark yoktu ( $p>0.05)$. Tedavi sonrasında her iki grupta da, tedavi öncesiyle kıyaslandığında VAS, THI ve AASS skorlarında istatistiksel olarak anlamlı düzelme saptanırken $(\mathrm{p}<0.05), K B$ grubunda sonuçlar daha iyiydi (Tablo 2 ve 3).

Tablo 1. Grupların fiziksel verileri

\begin{tabular}{lccc}
\hline & $\begin{array}{c}\text { KB } \\
(\mathrm{n}: 36)\end{array}$ & $\begin{array}{c}\text { EGZ } \\
(\mathrm{n}: 38)\end{array}$ & p \\
\hline Cinsiyet (K/E) & $27 / 9$ & $28 / 10$ & 0.914 \\
Yaş (yll) & $44.7 \pm 10.4$ & $45.7 \pm 10.7$ & 0.922 \\
VKI $\left(\mathrm{kg} / \mathrm{m}^{2}\right)$ & $30.2 \pm 3.7$ & $30.2 \pm 4.2$ & 0.881 \\
\hline
\end{tabular}

Veriler Ort. \pm SD veya oran olarak; K: kadın; E: erkek; VKI: vücut kütle indeksi; KB: kinezyolojik bantlama; EGZ: egzersiz

Tablo 2. Gruplararası VAS ve THI skorlarının karşılaştırılması

\begin{tabular}{lrrc}
\hline & KB (n:36) & EGZ (n:38) & p (KB vs EGZ) \\
\hline VAS & & & \\
TÖ & $8.65 \pm 1.50$ & $8.30 \pm 1.65$ & 0.67 \\
TS & $2.15 \pm 1.45$ & $4.48 \pm 1.11$ & 0.047 \\
$\mathbf{p}$ & $0.012^{\dagger}$ & $0.030^{\dagger}$ & \\
THI & & & \\
TÖ & $2.10 \pm 0.99$ & $2.07 \pm 1.11$ & 0.83 \\
TS & $0.27 \pm 0.42$ & $0.97 \pm 0.41$ & 0.041 \\
$\mathbf{p}$ & $0.020^{\dagger}$ & $0.032^{\dagger}$ & \\
\hline
\end{tabular}

Değerler ortalama \pm SD olarak; †: tedavi öncesi (TÖ) ve tedavi sonrası (TS) karşılaştırma (samples t-test, paired-samples t-test; $\mathrm{p}<0.05)$; VAS: vizüel analog skala; THI: topuk hassasiyet indeksi; KB: kinezyolojik bantlama; EGZ: egzersiz 
Tablo 3. Ayak-ayak bileği sonuç skalası (AASS) grup içi ve gruplararası karşılaştırılması

\begin{tabular}{|c|c|c|c|}
\hline & KB (n:36) & EGZ (n:38) & $\mathbf{p}(\mathrm{KB}$ vs EGZ) \\
\hline \multicolumn{4}{|c|}{ AASS ağrı } \\
\hline TÖ & $40.1 \pm 15.5$ & $40.3 \pm 17.2$ & 0.932 \\
\hline TS & $53.6 \pm 10.2$ & $47.8 \pm 10.3$ & 0.021 \\
\hline p & $0.018^{\dagger}$ & $0.038 \dagger$ & \\
\hline \multicolumn{4}{|c|}{ AASS belirtiler } \\
\hline TÖ & $51.5 \pm 21.2$ & $50.8 \pm 21.3$ & 0.712 \\
\hline TS & $66.2 \pm 21.0$ & $60.3 \pm 21.2$ & 0.033 \\
\hline $\mathbf{p}$ & $0.010^{\dagger}$ & $0.027^{\dagger}$ & \\
\hline \multicolumn{4}{|c|}{ AASS günlük yaşam } \\
\hline TÖ & $43.2 \pm 16.1$ & $45.5 \pm 16.3$ & 0.768 \\
\hline TS & $57.6 \pm 20.0$ & $51.6 \pm 20.2$ & 0.033 \\
\hline $\mathbf{p}$ & $0.011^{\dagger}$ & $0.029 \dagger$ & \\
\hline \multicolumn{4}{|c|}{ AASS spor-rekreasyon } \\
\hline TÖ & $40.1 \pm 22.1$ & $40.7 \pm 21.5$ & 0.941 \\
\hline TS & $59.9 \pm 24.9$ & $48.2 \pm 24.1$ & 0.024 \\
\hline $\mathbf{p}$ & $0.010^{\dagger}$ & $0.021^{\dagger}$ & \\
\hline \multicolumn{4}{|c|}{ AASS yaşam kalitesi } \\
\hline TÖ & $44.2 \pm 10.4$ & $43.7 \pm 11.0$ & 0.846 \\
\hline TS & $60.2 \pm 17.6$ & $50.2 \pm 18.1$ & 0.028 \\
\hline p & $0.012^{\dagger}$ & $0.022^{\dagger}$ & \\
\hline
\end{tabular}

Sonuçlar ortalama \pm SD olarak; †: tedavi öncesi (TÖ) ve tedavi sonrası (TS) karşılaştırma (samples t-test, paired-samples t-test; $\mathrm{p}<0.05$ )); KB: kinezyolojik bantlama; EGZ: egzersiz; AASS: ayak-ayak bileği sonuç skalası (ağrı, belirtiler, günlük yaşam, spor ve rekreasyonel aktiviteler, yaşam kalitesi alt ölçekleriyle)

\section{TARTISYMA}

Çalışmamızda PF'li hastalarda medial longitudinal arkı destekleyen KB uygulamasının VAS, THI ve AASS skorlarında istatistiksel olarak anlaml düzelme sağladığı gösterildi. Kinezyolojik bantlama kas iskelet sistemi hastalıklarında ve spor yaralanmalarının tedavisinde yaygın olarak kullanılmaktadır (11). Bu teknik, intersitisyel alanı arttırarak, kan ve lenf akımını arttırmakta, enflamasyon ve ağrıyı azaltarak iyileşmeyi hızlandırmaktadır $(11,12)$. Low-dye bantlama tekniği, plantar fasiit tedavisinde en yaygın kullanılan tekniklerden biridir $(13,15)$. Low-dye tekniğinin özellikle yürüme sırasında ayağın aşırı pronasyona gidişini azaltarak ağrıda azalmayı sağladığı düşünülmektedir (15-18). Low-dye bantlamanın, yürüme sırasında, ayak arka tarafı altındaki basıncı düşürdüğü çalışmalarla gösterilmiştir (15-18).

Aşırı pronasyon, ayak ve ayak bileği yapılarında artan strese neden olmaktadır, çünkü statik ve dinamik dengeleyiciler ayağın şeklini korumak için çalışmaktadır (19). Özellikle, tibialis posterior, ayağın inversion ve supinasyonunu kolaylaştırmak için kontraksiyon yaparken, eversiyon ve pronasyonun kontrol edilmesi için eksantrik olarak çalışmaktadır. Tibialis posterior kası naviküler ve medial küneiform kemiğe yapışarak medial longitudinal arkı desteklemek üzere hareket etmektedir. Bu nedenle aşırı pronasyon olduğunda, medial tibial stres sendromu ve plantar fasiit gibi yaralanmalar meydana gelebilmektedir $(19,20)$. 
Çalışmada özellikle medial longitudinal arkı destekleyen ve arkı yükselten farklı ve pratik bir bantlama tekniği uygulandı. Low-dye bantlama tekniğinde, ayağın aşırı pronasyona gidişini kontrol etmek, ayak arkını yükseltmek ve ayak hareketlerini kısıtlamak için elastik olmayan bez bantlar kullanılmaktadır (15-21). Burada, lowdye tekniğinden faklı olarak bez bant yerine, uygulaması daha pratik olan elastik bant uygulandl. Medial arkın kinezyolojik elastik bantlama ile desteklenmesi ve yükseltilmesinin, low-dye tekniğine benzer olarak ayağın pronasyona gidişini kontrol ettiği ve arkı yükselterek plantar fasyadaki gerginliği azalttığı bir olgu serisiyle de gösterilmiştir (22).

Ancak, bildiğimiz kadarıyla literatürde PF tedavisinde elastik bantla yapılan çalışma bulunmamakla birlikte, Abian ve ark.nın yaptıkları bir çalışmada, sporcularda ayak bileği yaralanmalarına karşı profilaktik olarak yapılan elastik bantlamanın, elastik olmayan bantlamaya göre daha konforlu ve ayak bileği hareketlerini kısıtlamada daha etkili olduğu bildirilmiştir (23). Yakın zamanda yapılmış klinik uygulama rehberlerine göre; medial longitudinal ark destekleri, silikon tabanlık, germe egzersizleri ve steroid enjeksiyonları birinci basamak tedavi önerileri arasındadır $(1,10)$. Silikon tabanlıklar ve ayak ortezleri ayağın pronasyonunu ve ayak arkının çöküşünü azaltarak, plantar fasyadaki gerginliği azaltmaktadır $(7,24,25)$. Ancak, klinik gözlemlerimize göre; silikon tabanlıklar ve ayak ortezlerinin ayakkabı içine uymaması, ya da hastaların büyük numara ayakkabı tercih etmek zorunda kalması gibi problemlerden dolayı uyum sağlayamayan hastalar ayak ortezlerini düzgün kullanmamaktadır.

Cheung ve ark.nın yaptıkları bir meta-analizde ayak pronasyonunu kontrol etmek için uygulanan kinezyolojik bantlamanın ayakkabı ve ayak ortezlerinden daha etkili olduğu bildirilmiştir (26). Bu sonuçlar bizim çalışmamızın verileri ile de uyumludur. Çalışmamızda silikon tabanlık kullanan grupta tedavi öncesine göre istatistiksel olarak anlamlı düzelme saptanırken, KB grubunda sonuçlar daha iyi bulundu. Bu sonuçlara göre medial longitudinal arkı destekleyen KB uygulamasının, silikon tabanlığa uyum sağlayamayan hastalar için iyi bir alternatif olabileceği düşünülmektedir. Benzer olarak, steroid enjeksiyon tedavisi de birinci basamak tedavi önerileri arasındadır $(1,7)$. Ancak, steroid enjeksiyonu sirasında tendonun yapisinda hasarlanma ve rüptür olabilmekte, uygulama hiperglisemiye sebep olmakta, hastalar topuk yağ yastığı atrofisi nedeniyle nüks eden ağriyla gelebilmektedir (27-30). KB'nin yan etkisi olmaması ve ağrısız bir uygulama olması nedeniyle ilk basamak tedavi seçenekleri arasında yer alabileceği düşünülmektedir. Ayrıca low-dye tekniğinden farklı olarak bez bant uygulaması yerine, elastik bant kullanılmasının uygulamayı pratikleștirdiği ve hastanın tedaviye uyumunu arttırdığı gözlemlenmiștir.

$\mathrm{Bu}$ çalışmanın en önemli kısıtlılığı kontrol grubunun olmamasıdır. Diğer bir kısıtlılık ise uzun dönem takip verilerinin olmamasıdır.

Sonuç olarak, medial longitudinal arkı destekleyen KB uygulamasının PF'li hastalarda ağrı, fonksiyonel durum ve yaşam kalitesi üzerine olumlu etkilerinin olduğu görülmüștür.

\section{KAYNAKLAR}

1. Salvioli S, Guidi M, Marcotulli G. The effectiveness of conservative, non-pharmacological treatment of plantar heel pain: A systematic review with metaanalysis. Foot (Edinb). 2017;33:57-67.

2. Goff JD, Crawford R. Diagnosis and treatment of plantar fasciitis. Am Fam Physician. 2011;84:676-82.

3. Roxas M. Plantar fasciitis: diagnosis and therapeutic considerations. Altern Med Rev. 2005;10:83-93.

4. Chang KV, Chen SY, Chen WS, et al. Comparative effectiveness of focused shock wave therapy of different intensity levels and radial shock wave therapy for treating plantar fasciitis: a systematic review and network meta-analysis. Arch Phys Med Rehabil. 2012;93:1259-68.

5. Tu P, Bytomski JR. Diagnosis of heel pain. Am Fam Physician. 2011;84:909-16.

6. League AC. Current concepts review: plantar fasciitis. Foot Ankle Int. 2008;29:358-66.

7. Yucel U, Kucuksen S, Cingoz HT, et al. Full-length silicone insoles versus ultrasound-guided corticosteroid injection in the management of plantar fasciitis: a randomized clinical trial. Prosthet Orthot Int. 2013;37:471-6.

8. Agyekum EK, Ma K. Heel pain: A systematic review. Chin J Traumatol. 2015;18:164-9. 
9. Ordahan B, Türkoğlu G, Karahan AY, et al. Extracorporeal shockwave therapy versus kinesiology taping in the management of plantar fasciitis: a randomized clinical trial. Arch Rheumatol. 2017;32:227-33.

10. Thomas JL, Christensen JC, Kravitz SR, et al. The diagnosis and treatment of heel pain: a clinical practice guideline-revision 2010. J Foot Ankle Surg. 2010;49(3 Suppl):S1-19.

11. Kase K, Wallis J, Kase T. Clinical Therapeutic Application of the Kinesiotaping Method. $3^{\text {rd }}$ ed. Tokyo: Ken Ikai Co Ltd; 2003. p.12.

12. Aquiler-Ferrándiz ME, Castro-Sánchez AM, MataránPeñarrocha GA, et al. Effects of kinesio taping on venous symptoms, bioelectrical activity of the gastrocnemius muscle, range of ankle motion, and quality of life in postmenopausal women with chronic venous insufficiency: a randomized controlled trial. Arch Phys Med Rehabil. 2013;94:2315-28.

13. Landorf KB, Radford JA, Keenan AM, et al. Effectiveness of low-Dye taping for the short therm management of plantar fasciitis. J Am Podiatr Med Assoc. 2005;95:525-30.

14. Karatepe AG, Günaydin R, Kaya T, et al. Validation of the Turkish version of the foot and ankle outcome score. Rheumatol Int. 2009;30:169-73.

15. Van Lunen B, Cortes $\mathrm{N}$, Andrus $\mathrm{T}$, et al. Immediate effects of a heel-pain orthosis and an augmented lowdye taping on plantar pressures and pain in subjects with plantar fasciitis. Clin J Sport Med. 2011;21:474-9.

16. Vicenzino B, McPoil TG, Russell T, et al. Anti-pronation tape changes foot posture but not plantar ground contact during gait. The Foot. 2006;16:91-7.

17. Harradine P, Herrington L, Wright R. The effect of Low Dye taping upon rear foot motion and position before and after exercises. The Foot. 2001;11:57-60

18. Vicenzino B, McPoil T, Buckland S. Plantar foot pressures after the augmented low dye taping technique. J Athl Train. 2007;42:374-80.

19. Plisky MS, Rauh MJ, Heiderscheit B, et al. Medial tibial stres syndrome in high school cross country runners: incidence and risk factors. J Orthop Sports Phys Ther. 2007;37:40-7.

20. Hintermann B, Nigg BM, Sommer C. Foot movement and tendon excursion: an in vitro study. Foot Ankle Int. 1994;15:386-95.

21. Franettovich MM, Chapman A, Vicenzino B. Tape that increases medial longitudinal arch height also reduces leg muscle activity: a preliminary study. Med Sci Sports Exerc. 2008;40:593-600.

22. Meier K, McPoil TG, Cornwall MW, et al. Use of anti pronation taping to determine foot orthose sprescription: a case series. Res Sports Med. 2008;16:257-71.

23. Abián-Vicén J, Alegre LM, Fernández-Rodríguez JM, et al. Prophylactic ankle taping: elastic versus inelastic taping. Foot Ankle Int. 2009;30:218-25.

24. Landorf KB, Keenan AM, Herbert RD. Effectiveness of foot orthoses to treat plantar fasciitis: a randomized trial. Arch Intern Med. 2006;166:1305-10.

25. Kitaoka HB, Luo ZP, Kura H, et al. Effect of foot orthoses on 3-dimensional kinematics of flat foot: a cadaveric study. Arch Phys Med Rehabil. 2002;83:876-9.

26. Cheung RT, Chung RC, Ng GY. Efficacies of different external controls for excessive foot pronation: a metaanalysis. Br j Sports Med. 2011;45:743-51.

27. Tatli YZ, Kapasi S. The real risks of steroid injections for plantar fasciitis, with a review of conservative therapies. Curr Rev Musculoskelet Med. 2009;2:3-9.

28. Kim C, Cashdollar MR, Mendicino RW, et al. Incidence of plantar fascia ruptures following corticosteroid injection. Foot Ankle Spec. 2010;3:335-7.

29. Acevedo JI, Beskin JL. Complications of plantar fascia ruptures associated with corticosteroid injections. Foot Ankle Int. 1998;19(2):91-7.

30. Brinks A, Koes BW, Volkers AC, et al. Adverse effects of extra-articular corticosteroid injections: a systematic review. BMC Musculoskeletal Disord. 2010;11:206. 